\title{
Design of a novel pulsed laser diode induced photoacoustic imaging system for tumor diagnosis (Withdrawal Notice)
}

Zhong Ren, Lvming Zeng, Guodong Liu, Zhen Huang

Zhong Ren, Lvming Zeng, Guodong Liu, Zhen Huang, "Design of a novel pulsed laser diode induced photoacoustic imaging system for tumor diagnosis (Withdrawal Notice)," Proc. SPIE 8329, Tenth International Conference on Photonics and Imaging in Biology and Medicine (PIBM 2011), 832905 (13 March 2012); doi: 10.1117/12.925857 


\title{
Design of a novel pulsed laser diode induced photoacoustic imaging system for tumor diagnosis (Withdrawal Notice)
}

\author{
Proc. SPIE 8329, 832905 (2011); http://dx.doi.org/10.1117/12.925857
}

Online Publication Date: 13 March 2012

Withdrawn from Publication: 17 May 2012

Conference Date: Wednesday 2 November 2011

Conference Location: Wuhan, China

Conference Title: Tenth International Conference on Photonics and Imaging in Biology and Medicine (PIBM 2011)

Conference Chairs: Qingming Luo, Lihong V. Wang, Valery V. Tuchin

Zhong Ren, Lvming Zeng, Guodong Liu, and Zhen Huang

J iangxi Science and Technology Normal Univ. (China)

This paper was presented at the SPIE conference indicated above and has been withdrawn from publication at the request of the authors. 